\title{
Tolerance to Acute Ischemia in Adult Male and Female Spontaneously Hypertensive Rats
}

\author{
J. BEŠÍIK ${ }^{1,2}$, O. SZÁRSZOI ${ }^{1,2}$, J. KUNEŠ ${ }^{2}$, I. NETUKA ${ }^{1,2}$, J. MALÝ ${ }^{1,2}$, F. KOLÁŘ ${ }^{2}$, \\ J. PIRK ${ }^{1}$, B. OŠŤÁDAL ${ }^{2}$.
}

Centre for Cardiovascular Research, ${ }^{1}$ Department of Cardiovascular Surgery, Institute for Clinical and Experimental Medicine and ${ }^{2}$ Institute of Physiology, Academy of Sciences of the Czech Republic, Prague, Czech Republic

Received April 5, 2006

Accepted June 22, 2006

On-line available June 22, 2006

\begin{abstract}
Summary
Clinical and experimental studies have repeatedly indicated that overloaded hearts have a higher vulnerability to ischemia/reperfusion injury. The aim of the present study was to answer the question whether the degree of tolerance to oxygen deprivation in hearts of spontaneously hypertensive rats (SHR) may be sex-dependent. For this purpose, adult SHR and their normotensive control Wistar Kyoto (WKY) rats were used. The isolated hearts were perfused according to Langendorff at constant pressure (proportionally adjusted to the blood pressure in vivo). Recovery of contractile parameters (left ventricular systolic, diastolic and developed pressure as well as the peak rate of developed pressure) was measured during reperfusion after $20 \mathrm{~min}$ of global no-flow ischemia in $5 \mathrm{~min}$ intervals. Mean arterial blood pressure was measured by direct puncture of carotid artery under light ether anesthesia in a separate group of animals. The degree of hypertension was comparable in both sexes of SHR. The recovery of contractile functions in SHR males and females was significantly lower than in WKY rats during the whole investigated period. There was no sex difference in the recovery of WKY animals; on the other hand, the recovery was significantly better in SHR females than in SHR males. It may be concluded that the hearts of female SHR are more resistant to ischemia/reperfusion injury as compared with male SHR. This fact could have important clinical implications for the treatment of cardiovascular disease in women.
\end{abstract}

Key words

Cardiac tolerance $\bullet$ Ischemia injury $\bullet$ Reperfusion injury $\bullet$ Spontaneously hypertensive rats $\bullet$ Gender differences

\section{Introduction}

Cardiac hypertrophy is an adaptive response that compensates for an increased workload by normalizing wall stress and preserving cardiac contractile function. In advanced stages, however, when the high workload is maintained, hypertrophy progresses to ventricular dilatation, contractile dysfunction and finally to heart failure (Katz 2001, Friehs and del Nido 2003). It has been recognized for more than 30 years that the hypertrophied 
heart shows a decreased tolerance to ischemia/reperfusion injury, with the first description of so-called "stone heart". Data from the Framingham Heart Study identify left ventricular hypertrophy as the single most important contributor to cardiovascular morbidity and mortality. This is particularly important in cardiac surgery, as left ventricular hypertrophy is frequently associated with postischemic contractile dysfunction. It has been found that cardiac tolerance to ischemic arrest during open-heart surgery depends on the degree of hypertrophy (Schaper et al. 1976) and duration of ischemia (Beyersdorf et al. 1980).

To analyze the tolerance of the hypertrophic heart to ischemia/reperfusion injury under experimental conditions, models such as isoproterenol treatment (Minor et al. 1994), renal hypertension (Harmsen et al. 1994), aortocaval shunt (Harmsen et al. 1994), thyroxine treatment ( $\mathrm{Yu}$ et al. 1997), saline drinking (Saupe et al. 2000, Shi et al. 2005), aortic constriction (Peyton et al. 1982, Gaasch et al. 1990, Snoeckx et al. 1990, Zhang and Su 1995, Yamamoto et al. 2001, Friehs and del Nido 2003), as well as spontaneous hypertension (Belichard et al. 1988, Snoeckx et al. 1989, 1993, Mill et al. 1998, Itter et al. 2004) have been used. In spite of the fact that the above mentioned experiments used different animal species (rats, rabbits, dogs), different end-points of injury (e.g. arrhythmias, contractile dysfunction, infarct size, mortality rate), and different stage of hypertrophy, they have confirmed the clinical observations that the hypertrophic myocardium is more susceptible to ischemic damage than the normal one. On the other hand, Saupe et al. (2000) have surprisingly observed in Dahl rats that during the natural history of left ventricular hypertrophy secondary to hypertension, a period occurs during which the response to ischemia is improved, probably by minimizing the size of the region of severe acidosis. Furthermore, Mozaffari and Schaffer (2003) found greater impairment of cardiac contractile function but reduced infarct size in rats with renal hypertension. They speculated that these results might be due to different factors regulating contractile function and affecting infarct size. Unfortunately, all mentioned experimental studies have used exclusively male animals; possible sexdependent changes have not been analyzed. However, sex hormones may play an important role in the development of ischemic heart disease. The results of numerous studies indicate that coronary heart disease morbidity and mortality occur about ten years later in women than in men (Vaccarino et al. 1995). Accordingly, experimental studies have repeatedly indicated significant sex differences in cardiac tolerance to ischemia; nonhypertrophied hearts of adult males have a higher vulnerability to ischemia/reperfusion injury than the normal hearts of female rats (Imahashi et al. 2004, Shinohara et al. 2004, Netuka et al. 2006).

The aim of the present study was, therefore, to answer the question whether the degree of cardiac tolerance to oxygen deprivation may be sex-dependent also in the hypertrophied heart since significant sex differences have been described in the left ventricular adaptation to pressure overload (Jain et al. 2002). For this purpose, adult male and female spontaneously hypertensive rats (SHR) and their appropriate controls, Wistar-Kyoto rats (WKY), have been used. Prominent myocardial hypertrophy is generally present in the SHR and is believed to be a consequence of sustained systemic hypertension, although it cannot be excluded that the development of cardiac hypertrophy in this rat strain is also caused by genetic factors. The blood pressure of SHR was usually found to be significantly higher compared with WKY already in newborns, characteristic acceleration mainly occurs between the 3rd and 10th week of age, when their blood pressure rapidly increases by $30 \%$ above that of WKY (Zicha and Kuneš 1999).

\section{Methods}

Adult (3-month-old) male and female SHR and their age-matched normotensive controls WKY were used. Rats were kept under standard conditions and had free access to water and a standard laboratory diet. The study was conducted in accordance with the Guide for the Care and Use of Laboratory Animals, published by the US National Institutes of Health (NIH Publication No. 85-23, revized 1996).

Adult male and female SHR and their WKY controls were divided into two groups: the first group was used for blood pressure measurement, the second group for the isolated heart procedure. Mean arterial blood pressure was measured by a direct puncture of carotid artery under light ether anesthesia; after cessation, the animals were killed by decapitation. Data were used for setting of constant perfusion pressures in the in vitro experiments.

For the isolated heart procedure the rats were anesthetized with sodium pentobarbital $(60 \mathrm{mg} / \mathrm{kg}$ i.p., Sanofi, France). Hearts were rapidly excised and perfused according to Langendorff under constant pressure 
Table 1. Mean arterial blood pressure in the WKY and SHR male and female rats.

\begin{tabular}{lllll}
\hline & Male WKY & Male SHR & Female WKY & Female SHR \\
\hline$n$ & 6 & 6 & 6 & 6 \\
$M A P(m m ~ H g)$ & $108 \pm 4.7$ & $160 \pm 5.9^{*}$ & $114 \pm 3.2$ & $151 \pm 3.4^{*}$ \\
\hline
\end{tabular}

$\mathrm{n}$ - number of animals; MAP - mean arterial blood pressure. Values are means \pm S.E.M.; $* P<0.05$ SHR vs. WKY.

Table 2. Weight parameters in the WKY and SHR male and female rats groups.

\begin{tabular}{lllll}
\hline & Male WKY & Male SHR & Female WKY & Female SHR \\
\hline$n$ & 8 & 9 & 8 & 10 \\
$B W(g)$ & $319 \pm 10$ & $312 \pm 8$ & $209 \pm 3^{\times}$ & $189 \pm 2^{* \times}$ \\
$H W(g)$ & $0.93 \pm 0.04$ & $1.22 \pm 0.03^{*}$ & $0.76 \pm 0.06^{\times}$ & $0.79 \pm 0.02^{\times}$ \\
$H W / B W$ & $2.9 \pm 0.1$ & $3.9 \pm 0.1^{*}$ & $3.6 \pm 0.3^{\times}$ & $4.2 \pm 0.1^{*}$
\end{tabular}

BW - body weight; HW - heart weight; HW/BW, relative weight of the heart; $n$ - number of animals. Values are means \pm S.E.M.; $* P<0.05$ SHR vs. WKY, $\times P<0.05$ female vs. male.

(perfusion pressure was proportionally adjusted to the blood pressure in vivo; for WKY male and female hearts $108 \mathrm{~cm} \mathrm{H}_{2} \mathrm{O}$ and $114 \mathrm{~cm} \mathrm{H}_{2} \mathrm{O}$, respectively, and for SHR male and female hearts $160 \mathrm{~cm} \mathrm{H}_{2} \mathrm{O}$ and $151 \mathrm{~cm} \mathrm{H}_{2} \mathrm{O}$, respectively, Table. 1) with non-recirculating KrebsHenseleit solutions containing (mmol/l): $\mathrm{NaCl} 118.0, \mathrm{KCl}$ 4.7, $\mathrm{CaCl}_{2}$ 1.25, $\mathrm{MgSO}_{4}$ 1.2, $\mathrm{NaHCO}_{3} 25.0, \mathrm{KH}_{2} \mathrm{PO}_{4} 1.2$ and glucose 7.0. The medium was saturated with $95 \% \mathrm{O}_{2}$ and $5 \% \mathrm{CO}_{2}(\mathrm{pH} 7.4)$ and maintained at $37{ }^{\circ} \mathrm{C}$. The left ventricle was vented at the apex and stimulated at 300 beats/min with platinum electrodes placed on the base of the right ventricle. The contractile function was measured with a non-elastic balloon inserted into the left ventricle via incision in the left atrium and connected to the pressure transducer (Hewlett-Packard 1280, USA). The balloon was gradually filled with water to give diastolic pressure of 7 to $10 \mathrm{~mm} \mathrm{Hg}$. The amplified pressure signal was monitored and immediately analyzed on a computer using our software. The left ventricular systolic (LVSP), diastolic (LVDP), developed pressure (LVDevP), and the peak rate of developed pressure $\left[(+\mathrm{dP} / \mathrm{dt})_{\max }\right]$ were expressed as the means of ten cardiac cycles during a 2s sampling period at selected time intervals. Coronary flow was measured by timed collection of coronary effluent and subsequently normalized to heart weight.

After $25 \mathrm{~min}$, during which the contractile parameters were allowed to stabilize, hearts were subjected to 20 -min global no-flow ischemia followed by
40 min of reperfusion. Global ischemia was induced by clamping the perfusate inflow line while the hearts were placed in a bath of Krebs-Henseleit solution saturated with $95 \% \mathrm{~N}_{2}$ and $5 \% \mathrm{CO}_{2}(\mathrm{pH} 7.4)$ and maintained at $37^{\circ} \mathrm{C}$. After restoration of flow, the functional parameters were recorded at 5-min intervals and their recovery was expressed as percentage of initial preischemic values. The hearts were weighed at the end of experiments.

\section{Statistics}

The results are expressed as means \pm S.E.M. Differences in the recovery of $(+\mathrm{dP} / \mathrm{dt})_{\max }$ and between the groups were compared by the Mann-Whitney $U$ test. One-way ANOVA or ANOVA for repeated measures and subsequent Student-Newman-Keuls test were used for comparison of differences in parametric variables within the group. Differences were assumed as statistically significant when $\mathrm{P}<0.05$.

\section{Results}

\section{Weight parameters and blood pressure}

The mean arterial blood pressure (MAP) of male and female SHR was significantly higher than that of WKY rats; there were no significant differences of MAP between male and female rats in either groups (Table 1).

The body weight (BW) and absolute heart 
Table 3. Baseline contractile parameters and coronary flow of the isolated perfused hearts of SHR and WKY male and female rats.

\begin{tabular}{lllll}
\hline & Male WKY & Male SHR & Female WKY & Female SHR \\
\hline$n$ & 8 & 9 & 8 & 10 \\
$\operatorname{LVSP}(\mathrm{mm} \mathrm{Hg})$ & $129.7 \pm 2.0$ & $163.5 \pm 4.3^{*}$ & $127.9 \pm 3.3$ & $153.2 \pm 4.0^{*}$ \\
LVDevP $(\mathrm{mm} \mathrm{Hg})$ & $121.6 \pm 2.0$ & $154.7 \pm 4.5^{*}$ & $119.2 \pm 3.3$ & $144.4 \pm 4.1^{*}$ \\
$(+d P / d t)_{\max }(\mathrm{mm} H \mathrm{Hg} / \mathrm{s})$ & $3946 \pm 133$ & $5144 \pm 252^{*}$ & $3804 \pm 155$ & $4544 \pm 157^{*}$ \\
$C F(\mathrm{ml} / \mathrm{min} / \mathrm{g})$ & $14.0 \pm 1.0$ & $15.8 \pm 0.7$ & $14.9 \pm 0.7$ & $15.9 \pm 0.5$ \\
\hline
\end{tabular}

LVSP - left ventricular systolic pressure; LVDevP - developed pressure; $(+\mathrm{dP} / \mathrm{dt})_{\max }$, peak rate of pressure development; CF, coronary flow; $\mathrm{n}$ - number of animals. Values are means \pm S.E.M. $* P<0.05$ SHR vs. WKY.

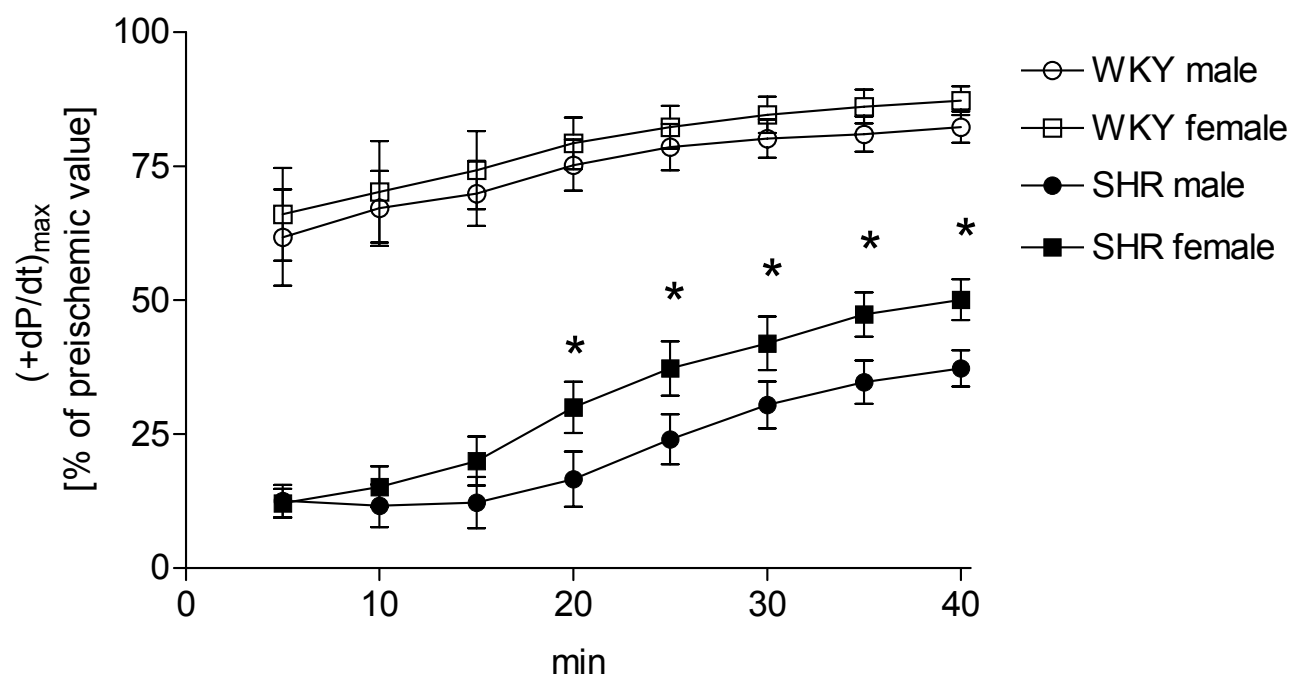

Fig. 1. Time course of recovery of peak rate of pressure development $\left[(+\mathrm{dP} / \mathrm{dt})_{\max }\right]$ during reperfusion after $20 \mathrm{~min}$ of global ischemia, expressed as percentage of preischemic values, in the SHR and WKY male and female animals. Values are means \pm S.E.M. $* P<0.05$ SHR female vs. SHR male.

weight (HW) of WKY and SHR male rats was significantly higher as compared with age-matched female animals (Table 2). HW and HW/BW ratios were significantly increased in the male SHR group as compared with the corresponding male WKY rats; BW was comparable in both groups. BW of SHR female rats was markedly reduced in comparison with the corresponding WKY group, the difference in absolute HW did not reach statistical significance, but HW/BW ratio of the SHR females was significantly higher in comparison with WKY rats and comparable with SHR males.

\section{Postischemic contractile dysfunction}

Baseline preischemic values of contractile parameters and coronary flow did not differ either between WKY male and female group, or between SHR male and female animals (Table 3). Contractile parameters of the SHR male and female hearts were significantly increased as compared with corresponding WKY controls.

The time course of the postischemic recovery of contractile function is shown in Figure 1. Recovery of the peak rate of pressure development $(+\mathrm{dP} / \mathrm{dt})_{\max }$ in SHR male and female rats was significantly lower during the whole investigated period when compared to WKY controls. There was no sex difference in the time course of recovery in WKY animals; on the other hand, the recovery in female SHR was significantly better as compared to male SHR.

Maximum recovery of $(+\mathrm{dP} / \mathrm{dt})_{\max }$ reached $82.8 \pm 3.1 \%$ of the preischemic value in the WKY male group and it did not differ from that in female WKY hearts (88.1 $\pm 2.8 \%$ ) (Fig. 2). Hearts of the SHR of either sex were more sensitive to acute ischemia as compared with WKY: recovery of contractile function was markedly decreased in SHR of both sexes (37.3 $\pm 3.4 \%$ in the male group; $50.2 \pm 3.8 \%$ in the female group). 


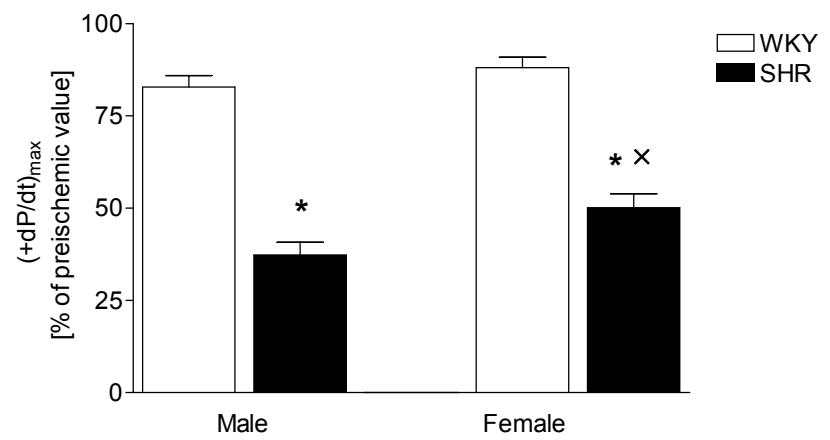

Fig. 2. Maximum recovery of peak rate of pressure development $\left[(+\mathrm{dP} / \mathrm{dt})_{\max }\right]$ during reperfusion after $20 \mathrm{~min}$ of global ischemia, expressed as percentage of preischemic values, in the SHR and WKY male and female animals. Values are means \pm S.E.M. $* P<0.05$ SHR vs. WKY,$\times P<0.05$ female vs. male.

However, hypertrophied hearts of adult SHR females were more tolerant to acute ischemia than hypertrophied hearts of adult SHR males.

\section{Discussion}

Our results demonstrate that cardiac tolerance to ischemia-reperfusion injury, as judged from the degree of postischemic contractile dysfunction, was significantly lower in SHR male and female hearts as compared with corresponding WKY controls. Moreover, cardiac tolerance in SHR was sex-dependent: recovery of female SHR hearts was significantly better than in SHR males despite the fact that the degree of hypertension was comparable.

The fact that the hypertrophied heart of SHR is significantly less tolerant to ischemia than that of normotensive controls is in good agreement with the previously published data (Belichard et al. 1988, Snoeckx et al. 1989, 1993, Itter et al. 2004). The mechanism responsible for the decreased tolerance of hypertrophied hearts to ischemia is likely to be a complex array of interactive events. During myocardial ischemia, hypertrophied hearts exhibit an accelerated loss of highenergy nucleotides, greater accumulation of tissue lactate and hydrogen ions, earlier onset of ischemic contracture, accelerated calcium overload during early reperfusion (Friehs and del Nido 2003), impaired sodium handling (Golden et al. 1994) and decreased NO availability. Moreover, during development of myocardial hypertrophy, myocytes enlarge and there may not be concomitant microvascular growth: when the area of myocardial tissue supplied by one capillary increases, delivery of oxygen as well as other nutrients is potentially impaired (Turek and Rakušan 1981, Batra and Rakušan 1992, Ashruf et al. 1999). The diminished microvascular supply in the hypertrophied heart was according to Friehs and del Nido (2003) temporally associated with the decline in contractility and with increased vulnerability to ischemia-reperfusion injury. These results indicate that the impaired glucose uptake and, potentially, impairment of all substrates available to the hypertrophied myocardium is due, at least in part, to decreased microvascular density.

To the best of our knowledge, this is the first study demonstrating that the hearts of adult female SHR are more tolerant to the ischemia-reperfusion injury as compared with the male myocardium, despite the fact that the degree of hypertension was comparable. On the other hand, in WKY controls the cardiac vulnerability to ischemia/reperfusion was comparable in both sexes, probably because of high recovery of contractility after $40 \mathrm{~min}$ of ischemia. We cannot exclude that more severe degree of ischemic injury might be more discriminative.

For the explanation of the gender differences in the cardiac tolerance to ischemia-reperfusion injury, a different response to hemodynamic overload has to be taken into consideration. Clinical studies have documented gender differences in the pattern of adaptive left ventricular hypertrophy in response to increased afterload, such as occurs in aortic stenosis and hypertension. Cardiac performance is more frequently preserved in female compared to male patients with a similar degree of aortic stenosis (Buttrick and Scheuer 1992). Douglas et al. (1998) and Weinberg et al. (1999) have observed a similar degree of left ventricular hypertrophy in the rat model of ascending aortic stenosis but earlier transition to failure manifested as left ventricular dilation and depressed systolic performance in male compared to female rats; analogous gender differences were also described in SHR (Pfeffer et al. 1982) and in Dahl salt-sensitive rats (Jain et al. 2002). Tamura et al. (1999) have demonstrated that the cardiac myocyte volume is significantly larger in male than in female SHR, suggesting a reduced adaptive hypertrophic reserve in males, which is likely to contribute to the higher morbidity and mortality of males with chronic heart failure. In this connection the question arises whether these gender-related differences in cardiac adaptation to a pressure overload are solely related to differences in geometric remodeling or may be, at least in part, related to differences in cardiac gene expression that precede the development of heart failure. Pressure- 
overload left ventricular hypertrophy in multiple animal models and human heart failure is associated with the upregulation of cardiac genes and isoforms that are normally expressed in fetal life and down-regulated during postnatal development (Matsui et al. 1995). Weinberg et al. (1999) found that messenger ribonucleic acid (mRNA) levels of both $\beta$-myosin heavy chain and atrial natriuretic factor were higher in male compared with female hearts in animals with aortic stenosis, despite a similar magnitude of left ventricular hypertrophy as well as the systolic load. Furthermore, mRNA levels of SERCA-2 were markedly depressed in male but not in female hypertrophied hearts. All these observations may contribute to the explanation of the depressed contractile reserve and increased ischemic vulnerability of the male overloaded heart.

Gender differences have frequently been attributed to female hormones; however, the underlying mechanisms responsible for the cardioprotective effect are still poorly understood. Brower et al. (2003) found that the extent of myocardial remodeling and the decrease in left ventricular function in ovariectomized females was comparable to changes reported for males. Lee et al. (2000) have found that acute administration of $17 \beta$ estradiol resulted in a significant, dose-dependent limitation of infarct size in both males and females. The infarct size-limiting effect of estrogen was abolished by 5-hydroxydecanoate, suggesting that the cardioprotective effect of this hormone may result from activation of myocardial mitochondrial $\mathrm{K}_{\mathrm{ATP}}$ channels. Molecular mechanisms probably also involve estrogen-induced production of NO (Node et al. 1997), an inhibitory effect on $\mathrm{Na}^{+} / \mathrm{Ca}^{2+}$ exchanger during myocardial infarction (Sugishita et al. 2001) and decreased $\mathrm{Na}^{+}$influx by an NO-dependent mechanism (Imahashi et al. 2004).

In conclusion, we have shown that hearts of female SHR are more tolerant to ischemia/reperfusion injury as compared with males, despite a comparable degree of hypertension. The results support the hypothesis that the mechanisms of cardiac adaptation to a pressure overload differ in male and female rats, suggesting an important role of the hormonal milieu in this process. This fact would have important clinical implications for the treatment of cardiovascular disease in women.

\section{Acknowledgement}

This study was supported by grant IGA MZ ND/7607-3, grant MSMT 1M0510, and grant AV0Z 50110509.

\section{References}

ASHRUF JF, INCE C, BRUINING HA: Regional ischemia in hypertrophic Langendorff-perfused rat hearts. $A m J$ Physiol 277: H1532-H1539, 1999.

BATRA S, RAKUŠAN K: Capillary network geometry during postnatal growth in rat hearts. Am J Physiol 262: H635H640, 1992.

BELICHARD P, PRUNEAU D, ROCHETTE L: Influence of spontaneous hypertension and cardiac hypertrophy on the severity of ischemic arrhythmias in the rat. Basic Res Cardiol 83: 560-566, 1988.

BEYERSDORF F, ELERT O, SATTER P: Determination of maximal ischemic tolerance of the human heart by ultrastructural recording of preischemic degree of myocardial hypertrophy and degeneration. Ann Thorac Surg 30: 356-363,1980.

BROWER GL, GARDNER JD, JANICKI JS: Gender mediated cardiac protection from adverse ventricular remodeling is abolished by ovariectomy. Mol Cell Biochem 251: 89-95, 2003.

BUTTRICK P, SCHEUER J. Sex-associated differences in left ventricular function in aortic stenosis of the elderly. Circulation 86: 1336-1338, 1992.

DOUGLAS PS, KATZ SE, WEINBERG EO, CHEN MH, BISHOP SP, LORELL BH: Hypertrophic remodeling: gender differences in the early response to left ventricular pressure overload. J Am Coll Cardiol 32: 1118$1125,1998$.

FRIEHS I, DEL NIDO PJ: Increased susceptibility of hypertrophied hearts to ischemic injury. Ann Thorac Surg 75 : S678-S684, 2003.

GAASCH WH, ZILE MR, HOSHINO PK, WEINBERG EO, RHODES DR, APSTEIN CS: Tolerance of the hypertrophic heart to ischemia. Studies in compensated and failing dog hearts with pressure overload hypertrophy. Circulation 81: 1644-1653, 1990. 
GOLDEN AL, BRIGHT JM, POHOST GM, PIKE MM: Ischemic dysfunction and impaired recovery in hypertensive hypertrophied hearts is associated with exaggerated intracellular sodium accumulation. Am J Hypertens 7: 745 $754,1994$.

HARMSEN E, SCHOEMAKER R, YU J, RUZICKA M, LEENEN FH: Sensitivity to ischaemic ATP breakdown in different models of cardiac hypertrophy in rats. J Hypertens 12: 49-57, 1994.

IMAHASHI K, LONDON RE, STEENBERGEN C, MURPHY E: Male/female differences in intracellular Na regulation during ischemia/reperfusion in mouse heart. J Mol Cell Cardiol 37: 747-753, 2004.

ITTER G, JUNG W, JURETSCHKE P, SCHOELKENS BA, LINZ W: A model of chronic heart failure in spontaneous hypertensive rats (SHR). Lab Anim 38: 138-148, 2004.

JAIN M, LIAO R, PODESSER BK, NGOY S, APSTEIN CS, EBERLI FR: Influence of gender on the response to hemodynamic overload after myocardial infarction. Am J Physiol 283: H2544-H2550, 2002.

KATZ AM: Physiology of the Heart. Lippincott Williams and Wilkins, Philadelphia, 2001.

LEE TM, SU SF, TSAI CC, LEE YT, TSAI CH: Cardioprotective effects of 17 beta-estradiol produced by activation of mitochondrial ATP-sensitive $\mathrm{K}^{+}$channels in canine hearts. J Mol Cell Cardiol 32: 1147-1158, 2000.

MATSUI H, MACLENNAN DH, ALPERT NR, PERIASAMY M: Sarcoplasmic reticulum gene expression in pressure overload-induced cardiac hypertrophy in rabbit. Am J Physiol 268: C252-C258, 1995.

MILL JG, NOVAES MA, GALON M, NOGUEIRA JB, VASSALLO DV: Comparison of the contractile performance of the hypertrophied myocardium from spontaneous hypertensive rats and normotensive infarcted rats. Can $J$ Physiol Pharmacol 76: 387-394, 1998.

MINOR T, ISSELHARD W, STURZ J: Recovery of healthy and hypertrophied hearts after global ischemia and gradual reperfusion. Ann Cardiol Angeiol 43: 395-399, 1994.

MOZAFFARI MS, SCHAFFER SW: Effect of hypertension and hypertension-glucose intolerance on myocardial ischemic injury. Hypertension 42: 1042-1049, 2003.

NETUKA I, SZÁRSZOI O, MALÝ J, BEŠÍK J, NECKÁŘ J, KOLÁŘ F, OŠŤÁDALOVÁ I, PIRK J, OŠŤÁDAL B: Effect of perinatal hypoxia on cardiac tolerance to acute ischemia in adult male and female rats. Clin Exp Pharmacol Physiol 33: 714-719, 2006.

NODE K, KITAKAZE M, KOSAKA H, MINAMINO T, FUNAYA H, HORI M: Amelioration of ischemia and reperfusion-induced myocardial injury by $17 \beta$-estradiol: role of nitric oxide and calcium activated potassium channels. Circulation 96: 1953-1963, 1997.

PEYTON RB, VAN TRIGT P, PELLOM GL, JONES RN, SINK JD, WECHSLER AS: Improved tolerance to ischemia in hypertrophied myocardium by preischemic enhancement of adenosine triphosphate. $J$ Thorac Cardiovasc Surg 84: 11-15, 1982.

PFEFFER JM, PFEFFER MA, FLETCHER P, FISHBEIN MC, BRAUNWALD E: Favorable effects of therapy on cardiac performance in spontaneously hypertensive rats. Am J Physiol 242: H776-H784, 1982.

SAUPE KW, LIM CC, INGWALL JS, APSTEIN CS, EBERLI FR: Comparison of hearts with 2 types of pressureoverload left ventricular hypertrophy. Hypertension 35: 1167-1172, 2000.

SCHAPER J, SCHWARZ F, FLAMENG W: Tolerance to ischemia in the human heart. Recent Adv Stud Cardiac Struct Metab 12: 513-517, 1976.

SHI Y, HUTCHINS W, OGAWA H, CHANG CC, PRITCHARD KA JR, ZHANG C, KHAMPANG P, LAZAR J, JACOB HJ, RAFIEE P, BAKER JE: Increased resistance to myocardial ischemia in the Brown Norway vs. Dahl S rat: role of nitric oxide synthase and Hsp90. J Mol Cell Cardiol 38: 625-635, 2005.

SHINOHARA T, TAKAHASHI N, OOIE T, ICHINOSE M, HARA M, YONEMOCHI H, SAIKAWA T, YOSHIMATSU H. Estrogen inhibits hyperthermia-induced expression of heat-shock protein 72 and cardioprotection against ischemia/reperfusion injury in female rat heart. J Mol Cell Cardiol 37: 1053-1061, 2004.

SNOECKX LH, VAN DER VUSSE GJ, VAN DER VEEN FH, COUMANS WA, RENEMAN R: Recovery of hypertrophied rat hearts after global ischemia and reperfusion at different perfusion pressures. Pflugers Arch 413: 303-312, 1989. 
SNOECKX LH, VAN DER VUSSE GJ, COUMANS WA, RENEMAN RS: The effects of global ischemia and reperfusion on compensated hypertrophied rat hearts. J Mol Cell Cardiol 22: 1439-1452, 1990.

SNOECKX LH, VAN DER VUSSE GJ, COUMANS WA, WILLEMSEN PH, RENEMAN R: Differences in ischaemia tolerance between hypertrophied hearts of adult and aged spontaneously hypertensive rats. Cardiovasc Res 27 : 874-881, 1993.

SUGISHITA K, SU Z, LI F, PHILIPSON KD, BARRY WH: Gender influences $\left[\mathrm{Ca}^{2+}\right]$ i during metabolic inhibition in myocytes overexpressing the $\mathrm{Na}^{+}-\mathrm{Ca}^{2+}$ exchanger. Circulation 104: 2101-2106, 2001.

TAMURA T, SAID S, GERDES AM: Gender-related differences in myocyte remodeling in progression to heart failure. Hypertension 33: 676-680, 1999.

TUREK Z, RAKUŠAN K: Lognormal distribution of intercapillary distance in normal and hypertrophic rat heart as estimated by the method of concentric circles: its effect on tissue oxygenation. Pflugers Arch 391: 17-21, 1981.

VACCARINO V, KRUMHOLZ HM, BERKMAN LF, HORWITZ RI: Sex differences in mortality after myocardial infarction. Is there evidence for an increased risk for women? Circulation 91: 1861-1871, 1995.

WEINBERG EO, THIENELT CD, KATZ SE, BARTUNEK J, TAJIMA M, ROHRBACH S, DOUGLAS PS, LORELL B: Gender differences in molecular remodeling in pressure overload hypertrophy. J Am Coll Cardiol 34: 264$273,1999$.

YAMAMOTO H, YAMAMOTO F, GOH K, SASAJIMA T: Reduced tolerance of global ischemia in the hypertrophied heart. Effect of coronary flow regulation during reperfusion on postischemic recovery. Jpn J Thorac Cardiovasc Surg 49: 287-295, 2001.

YU F, DAI DZ, AN LF, GUO XF: Heart hypertrophy induced by levothyroxine aggravates ischemic lesions and reperfusion arrhythmias in rats. Zhongguo Yao Li Xue Bao 18: 71-74, 1997.

ZHANG Y, XU S: Increased vulnerability of hypertrophied myocardium to ischemia and reperfusion injury. Relation to cardiac renin-angiotensin system. Chin Med J 108: 28-32, 1995.

ZICHA J, KUNEŠ J: Ontogenetic aspects of hypertension development: analysis in the rat. Physiol Rev 79: 1227-1282, 1999.

\section{Corresponding author}

Ondrej Szárszoi, Department of Cardiovascular Surgery, Institute for Clinical and Experimental Medicine, Vídeňská 1958/9, 14021 Prague 4, Czech Republic. Fax: 420261081 362. E-mail: onsz@medicon.cz. 